\title{
Erratum to: 30 Years of Research on Entry Mode and Performance Relationship: A Meta-Analytical Review
}

\author{
Hongxin Zhao' ${ }^{1}$ Jieqiong $\mathrm{Ma}^{2} \cdot$ Jie Yang $^{3}$
}

Published online: 21 December 2017

(C) Springer-Verlag GmbH Germany 2017

\section{Erratum to: Manag Int Rev (2017) 57:653-682 DOI 10.1007/s11575-017-0314-2}

1. Under Section 5.2, page 678, "Brouthers and Xu (2002)'s" should be replaced with "Brouthers' study (2002) that won...".

2. Accordingly this following reference should be added to Reference:

Brouthers, K. (2002). Institutional, cultural and transaction cost influences on entry mode choice and performance. Journal of International Business Studies, 33(2), 203-221.

3. A noticeable start of integrating different theories to explain E-P relationship is Brouthers' study (2002) that won 2013's Journal of International Business Studies decade award.

4. In Table 2, page 659, Brouthers and Xu (2002), “2003” should be replaced with "2002".

5. In Table 2, page 660, Belderbos et al. (2004), "Belderbos et al. (2004)" should be replaced with "Belderbos et al. (2014).

\footnotetext{
The online version of the original article can be found under doi:10.1007/s11575-017-0314-2.
}

Hongxin Zhao

zhaox@slu.edu

1 Saint Louis University, Saint Louis, USA

2 Hofstra University, Hempstead, USA

3 University of Texas at Tyler, Tyler, USA 